\title{
Comparative Study of Synergistic Effects of Antibiotics with Triangular Shaped Silver Nanoparticles, Synthesized Using UV-Light Irradiation, on Staphylococcus aureus and Pseudomonas aeruginosa
}

\author{
Sonali Saha*, Mohmmad Manzar Malik, Mohmmad Shums Qureshi \\ Department of Physics, Maulana Azad National Institute of Technology (M.A.N.I.T.), Bhopal, India \\ Email: pronit01@gmail.com, manzar.malik@gmail.com, shumsqureshi@rediffmail.com
}

Received 8 June 2014; revised 2 July 2014; accepted 16 July 2014

Copyright (C) 2014 by authors and Scientific Research Publishing Inc.

This work is licensed under the Creative Commons Attribution International License (CC BY).

http://creativecommons.org/licenses/by/4.0/

(c) (7) Open Access

\begin{abstract}
In the present work, a comparative study of antibacterial activity and synergistic effects of triangular silver nanoparticles in combination with two standard antibiotics is discussed for Staphylococcus aureus and Pseudomonas aeruginosa. A green route was developed to synthesise silver nanoparticles in which silver oxalate was taken as precursor, black tea leaves extract as surfactant and chitin as a stabilizing agent. A grey coloured colloidal solution of silver nanoparticles was obtained which was characterized by using various techniques like X-ray diffractometer (XRD), transmission electron microscopy (TEM) and UV-visible spectroscopy. Anti-bacterial studies gave approximately equal inhibition zones for both the combinations which states that silver nanoparticles are to be equally effective and synergistic effects were clearly observed in case of $P$. aeruginosa.
\end{abstract}

\section{Keywords}

Triangular Silver Nanoparticle, Black Tea Leaves Extract, UV-Irradiation, Staphylococcus aureus, Pseudomonas aeruginosa, Ampicillin and Gentamycin

\section{Introduction}

Nowadays, among metal nanoparticles, silver is gaining popularity, because it exhibits completely new and im-

*Corresponding author.

How to cite this paper: Saha, S., et al. (2014) Comparative Study of Synergistic Effects of Antibiotics with Triangular Shaped Silver Nanoparticles, Synthesized Using UV-Light Irradiation, on Staphylococcus aureus and Pseudomonas aeruginosa. Journal of Biomaterials and Nanobiotechnology, 5, 186-193. http://dx.doi.org/10.4236/jbnb.2014.53022 
proved properties. At nanoscale range, the particle size leads to large surface area per mass where a large number of atoms are in immediate contact and available for reaction. This size, morphology, stability and properties (chemical and physical) of the metal nanoparticles are strongly influenced by the experimental conditions [1] [2]. Hence, the design of a synthesis method in which the size, morphology, stability and properties are controlled, has become a thrust area [3] of research.

It is well known from ancient times that silver nanoparticles are very useful for biomedical applications due to their antibacterial activity. Antibacterial activity of the silver-containing materials can be used, for example, in medicine to reduce infections in burn treatment [4] [5] and arthroplasty [6] as well as to prevent bacteria colonization on prostheses [7] catheters [8] [9] vascular grafts [10], dental materials [11], stainless steel materials [12] and human skin [13] [14]. However, with time, the use of silver has reduced as an anti-infection agent due to the advent of antibiotics and other disinfectants and the poorly understood mechanisms of their toxic effects. From studies done by researchers on the synthesis and the antibacterial activity of silver nanoparticles, we find that most of the studies are limited upon interaction of spherical silver nanoparticles with bacterial cell wall [15] [16]. The work done by Pal, et al. [17] was the first study of the effect of shape of nanoparticles on bacterial cell. However, resistance of bacteria to bactericides and antibiotics has increased in recent years. Some antimicrobial agents are extremely irritant and toxic. Hence there is a need to find ways to formulate green and less toxic materials. Plant extracts play an important role in remediation of toxic metals through reduction of the metal ions [18]. Silver nanoparticle are synthesized from various parts of the herbal plants like bark of Citrus limon (Prathna, et al., 2011), cinnamon (Sathishkumar, et al., 2009), tannic acid (Sivaraman, et al., 2009), neem leaves (Tripathi, et al., 2009) and various plant leaves (Song and Kim, 2008).

In the present synthesis route, the author has developed a green route by using tea leaf extract as capping agent, UV-irradiation source as a reducing agent and chitin flakes as stabilizing agent. Black tea leaves contains antioxidants that play a major role in protecting the body against illnesses such as cancer and heart ailments. Compounds of silver like silver oxalate $\left(\mathrm{Ag}_{2} \mathrm{C}_{2} \mathrm{O}_{4}\right)$ are photosensitive and yield metallic silver upon the exposure to UV light in the presence of capping agents. Studies [17] [18] show that antimicrobial formulations of silver in the form of nanoparticles could be used as effective bactericidal materials. In the present work, synergistic effect of silver nanoparticles is studied in combination with two standard antibiotics against gram positive and gram negative bacteria. A comparative study between the two standard antibiotics for antibacterial activity and synergistic effects was also conducted.

\section{Materials and Method}

\subsection{Chemicals Used}

Materials used for the synthesis of silver nanoparticles are AR grade silver nitrate $\left(\mathrm{AgNO}_{3}\right)$ and oxalic acid purchased from Merck, India, black tea leaves of red label, Brooke Bond Company, deionized water (Ultra Pure) and chitin flakes of Himedia, CAS No.: 1398-61-4.

\subsection{Preparation of Silver Oxalate}

Silver oxalate was prepared by mixing $50 \mathrm{ml}$ solution of $0.5 \mathrm{M} \mathrm{AgNO}_{3}$ (Merck, 99\%) with $30 \mathrm{ml}$ of $0.5 \mathrm{M}$ oxalic acid (Merck, 99\%). The white formed precipitate was filtered washed with distilled water, dried in an air oven for one hour and stored in a dark bottle.

\subsection{Preparation of Tea Extract}

A $50 \mathrm{ml}$ volumetric flask was filled up to the mark with boiling water and $0.5 \mathrm{gm}$ of tea grains were weighed and transferred to this flask and filtered immediately using Whattman filter paper.

\subsection{Synthesis of Colloidal Silver Nanoparticles}

Figure 1 shows the experimental set up of the experiment. Experiment was conducted at room temperature. For the synthesis of colloidal solution, $0.02 \mathrm{gm}$ of $\mathrm{Ag}_{2} \mathrm{C}_{2} \mathrm{O}_{4}$ and $20 \mathrm{ml}$ doubly distilled water was taken in a three neck round bottom flask and stirred for $35 \mathrm{~min}$ in dark. Vacuum was created in the flask of the order of $10^{-3} \mathrm{~mm}$ of $\mathrm{Hg}$, followed by UV radiation of strength $256 \mathrm{~nm}$. During the irradiation process no cut-off filter was used. As soon as it is 


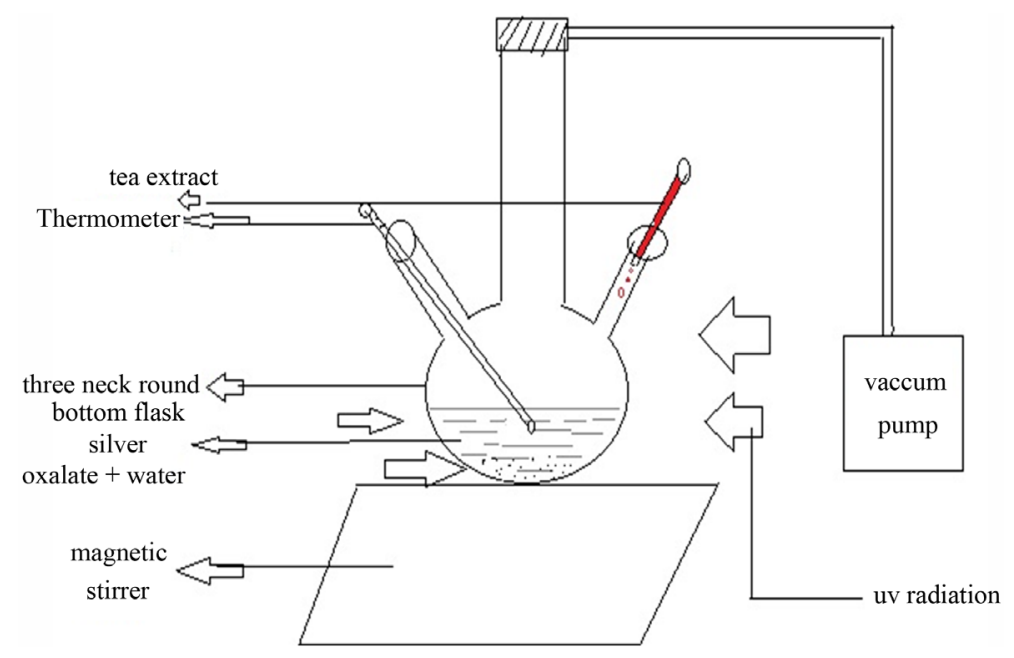

Figure 1. Experimental set-up.

exposed to UV irradiation, $10 \mathrm{ml}$ of tea extract is added to the solution using a syringe fitted in the cork, placed at one of three necks of the flask. Initially a plane yellow colloidal solution was formed. Then $0.01 \mathrm{gm}$ chitin flakes were added to the solution and process was carried further for a period of $1 \mathrm{hr}$. Finally, a grey coloured colloidal solution was obtained. The resultant colloid was washed by centrifugation several times.

\subsection{Antibacterial Studies}

For the comparative study, $1 \mathrm{ml}$ of as-synthesized colloidal solution of silver nanoparticles was taken with 10 mcg of ampicillin and with $10 \mathrm{mcg}$ of gentamicin for 15 minutes separately. Total solution, plated on Soya bean casein digest agar, was incubated at $37^{\circ} \mathrm{C}$ for $48 \mathrm{hr}$. Zone readings were taken for both. The test was conducted at Micro Bio Laboratory Thane (Maharashtra, India).

\section{Results and Discussions}

Silver oxalate was freshly prepared in the in-house set up. As-synthesised silver oxalate was characterized using XRD (Rigaku Miniflex II). The XRD pattern, Figure 2, of silver oxalate matches with JCPDS file No. 22-1335 indicating primitive monoclinic system. The silver oxalate thus obtained was further characterized using SEM (JSM 6390 A Model). The SEM images of as-synthesised silver oxalate is shown in Figure 3 which indicates irregular shaped silver oxalate particles approximately of size in the range of $500-750 \mathrm{~nm}$.

Silver oxalate, thus obtained, was then slowly exposed to UV irradiation along with the addition of black tea leaves extract and chitin flakes. Initially the precursor was exposed for time duration of 30 minutes. The XRD pattern of the precursor, silver oxalate (Figure 4) revealed that when sample was exposed for a time interval of 30 minutes, silver oxalate was partially decomposed to generate silver.

Therefore in order to reduce silver oxalate completely, the exposure time of UV-irradiation was increased to 1 hour. After 1 hr treatment, sample was again characterized using XRD. Figure 5 shows XRD pattern for 1 hour UV irradiation. The graph shows pure peaks of silver which are well in accordance with JCPDS file No. 040783. The diffraction profiles of as-synthesised face centred silver are obviously broadened as compared with bulk silver confirming the formation of silver nanoparticles. Thus for $1 \mathrm{hr}$ duration of UV irradiation, silver oxalate was completely decomposed rendering pure silver nanoparticles.

Silver oxalate decomposes under UV irradiation to give metallic silver and $\mathrm{CO}_{2}$ gas. This is due to the high photosensitivity of $\mathrm{Ag}_{2} \mathrm{C}_{2} \mathrm{O}_{4}$ [19]. The decomposition of oxalate occurs rapidly under UV radiation to yield metallic Ag as shown in Equation (1) because this decomposition of $\mathrm{Ag}_{2} \mathrm{C}_{2} \mathrm{O}_{4}$ is thermodynamically favourable due to the suitable reduction potentials of oxalate [20].

$$
\mathrm{Ag}_{2} \mathrm{C}_{2} \mathrm{O}_{4}(\mathrm{~s}) \rightarrow \mathrm{Ag}(\mathrm{g})+2 \mathrm{CO}_{2}(\mathrm{~g})
$$

In the presence of UV-irradiation di-anion of silver oxalate gets excited and thus decomposes into $\mathrm{CO}_{2}$, for- 


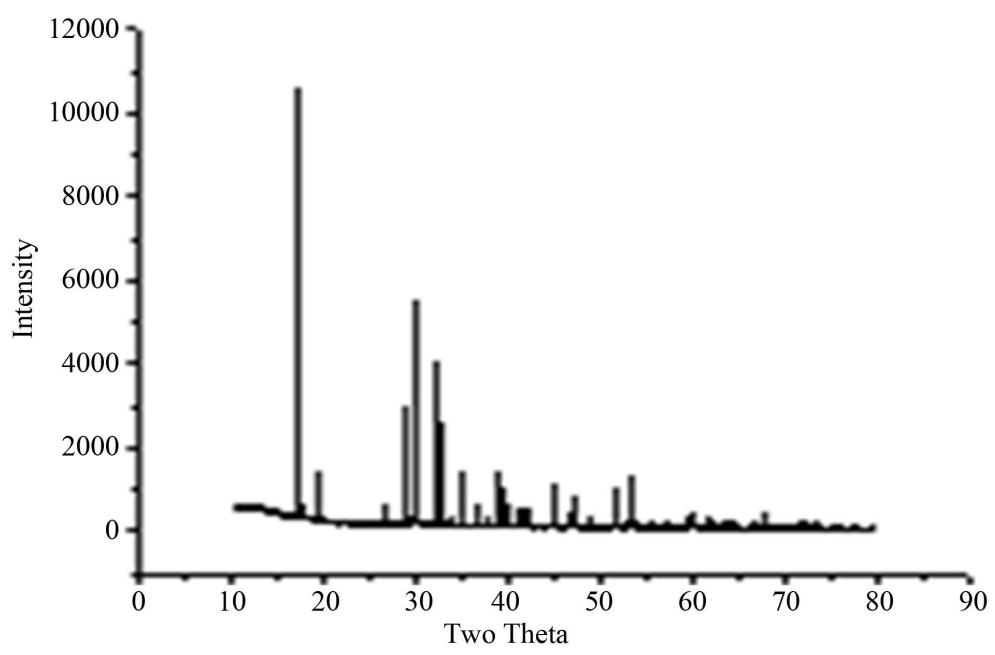

Figure 2. XRD graph of silver oxalate.

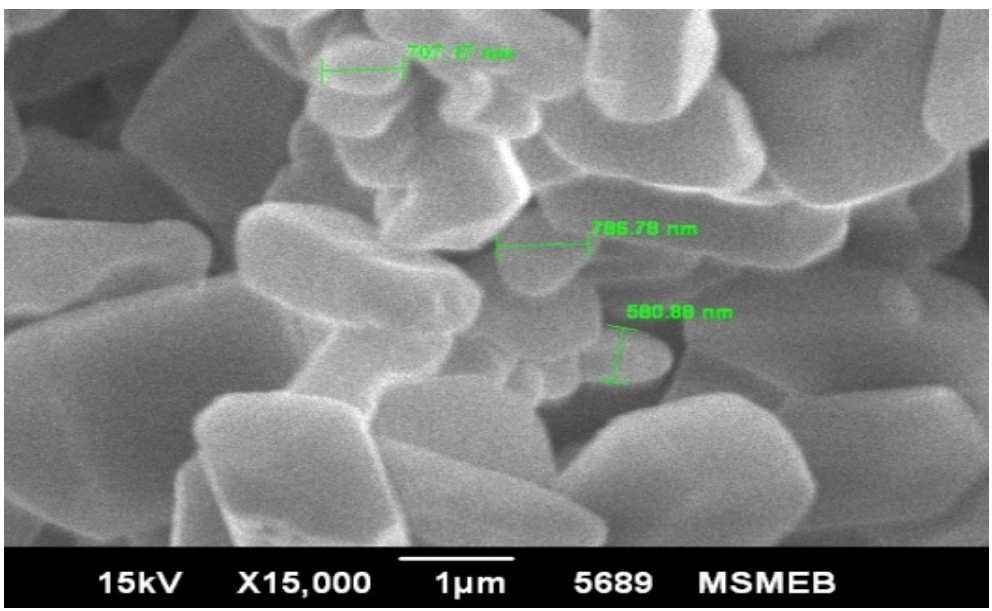

Figure 3. SEM images of silver oxalate.

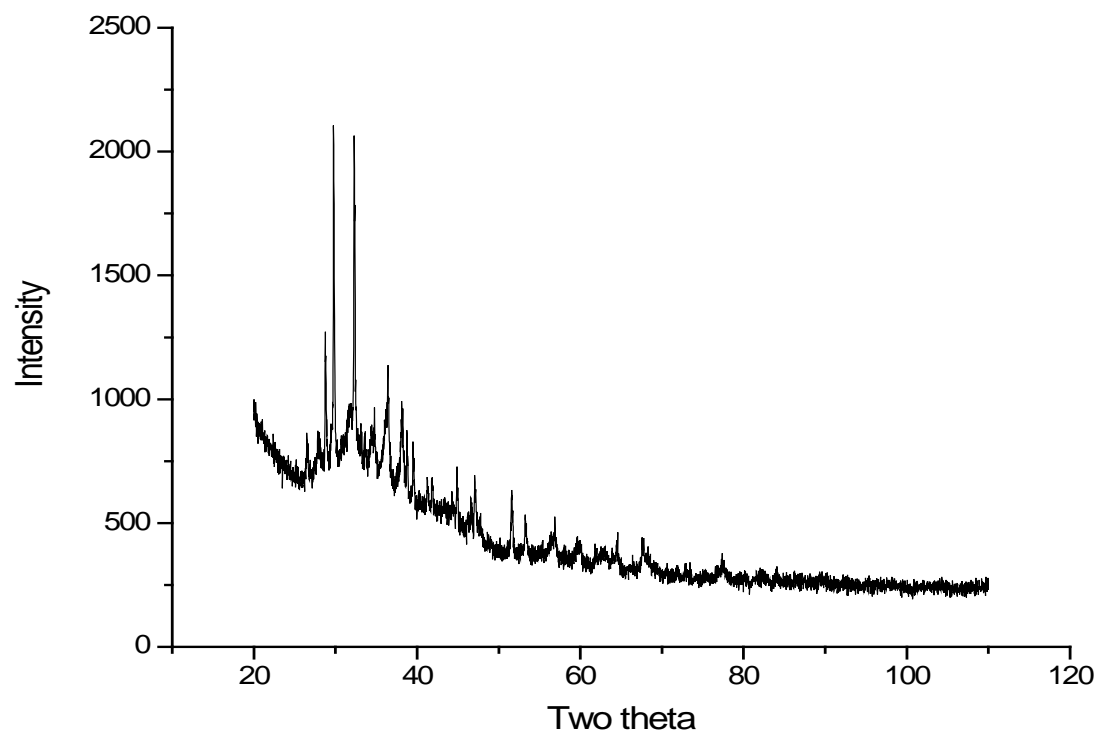

Figure 4. XRD pattern of sample (30 minute of UV-irradiation). 


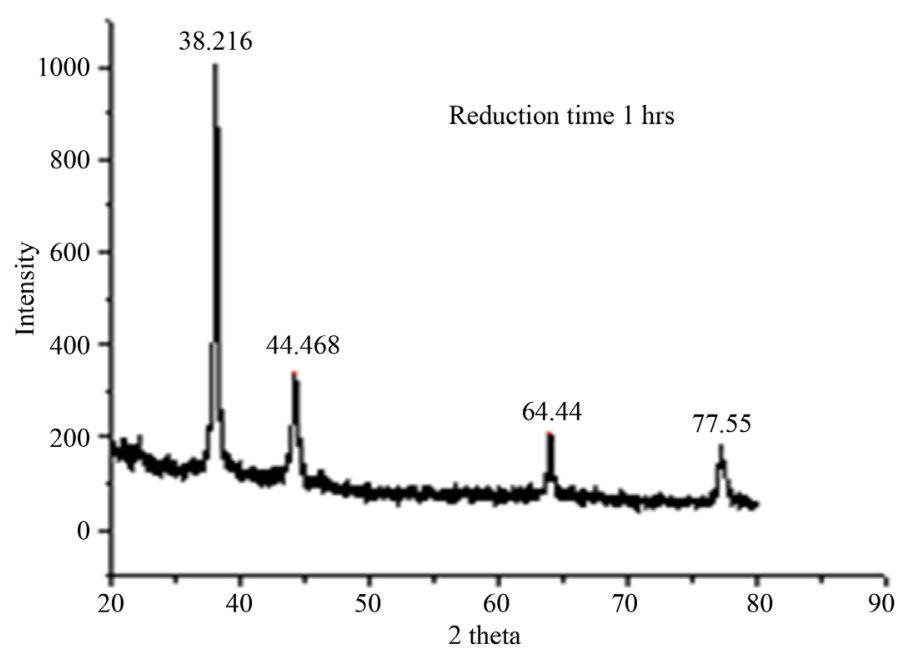

Figure 5. XRD graph of as-synthesised Ag nano particles for 1 hour UV-irradiation.

mation of $\mathrm{CO}_{2}$ can be proved by the appearance of the white precipitate in the baryata solution [21]. To understand the mechanism of the reaction during the decomposition, we see that electron is continuously transferred from silver ion to form silver metal [19]. These silver atoms start to form particles after getting sufficient concentration.

The as-synthesised silver nanoparticles were also characterized using TEM. TEM images shown in Figure 6(a) and Figure 6(b) reveal triangular shaped silver nanoparticles. The surface morphology of as-synthesised Ag nanoparticles may be attributed to the fact that when reduction rate is slow, triangular shaped nanoparticles are synthesized [22]. The average size of nanoparticles obtained was around $50 \mathrm{~nm}$. The size control of nano particles is determined by factors such as precursor concentration, molar ratio between surfactant and precursor, as well as the selective absorption of surfactant to different crystal facets [23] [24].

Here tea extract acts as capping agent only [25]. UV-vis spectroscopy was done to confirm the formation of nanopaticles and determine the concentration of the colloidal solution. UV-visible graph of the as-synthesized silver nanoparticles is shown in Figure 7.

From the UV-vis graph, it is observed that absorbance peak is obtained at 520nm which is the characteristic peak for triangular shaped silver nanoparticles [26]. Concentration of the colloidal solution for first configuration was calculated using the UV-vis graph and Beer-Lambert law:

$$
A=\varepsilon \cdot c \cdot l
$$

where $A$ is the absorbance; $\varepsilon$ is molar extinction coefficient; $C$ is the concentration of the solution; $l$ is the dimension of the cuvette. Molar extinction coefficient for silver nanoparticles in water is calculated using Mietheory based power law:

$$
\varepsilon=A \cdot d^{\gamma}, A=4.2 \times 10^{8} \mathrm{M}^{-1} \cdot \mathrm{cm}^{-1}, \gamma=0.77
$$

for diameter of Ag np, $d>38 \mathrm{~nm}$ [27].

Here $A=0.98623, l=1 \mathrm{~cm}$. Thus

$$
\begin{aligned}
C & =A / \varepsilon l=0.98623 / 4.2 \times 10^{8} \times(50)^{0.77} \\
& =1.01 \times 10^{-4} \text { Moles } / \text { litre }=1.01 \times 10^{-4} \times 107.8682 / 1000 \\
& =10.8-11 \mathrm{ppm}
\end{aligned}
$$

Total concentration of the solution is $10 \times 11=110 \mathrm{ppm}$ as for UV-vis spectroscopy the 10 fold dilution of the solution was taken.

\section{Antimicrobial Study}

Silver nanoparticles have received considerable attention as antimicrobial agents and have been shown to be an 


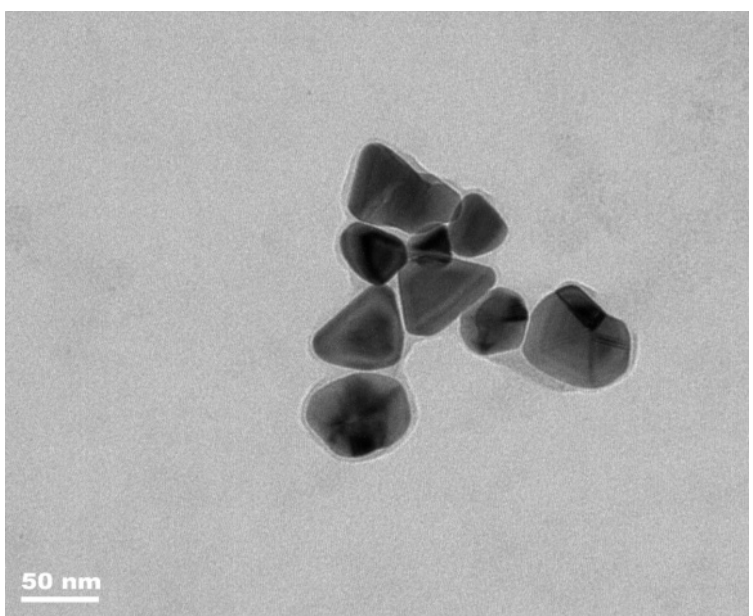

(a)

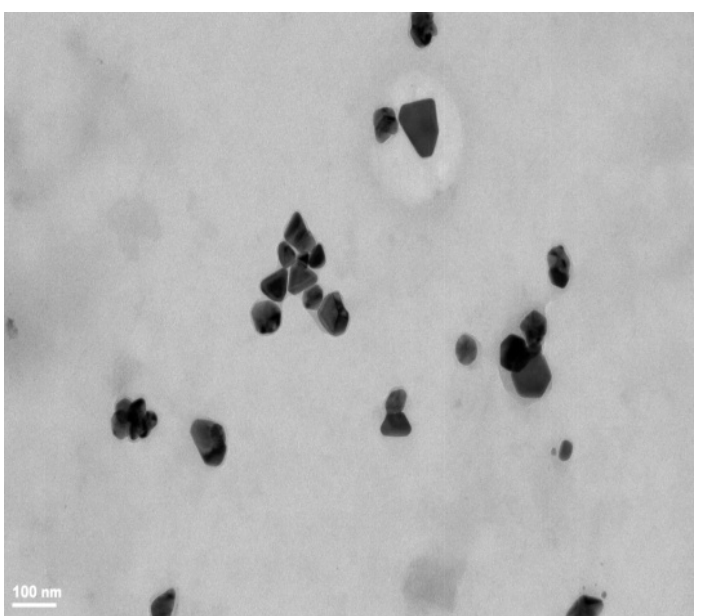

(b)

Figure 6. (a) (b) Tem images of as-synthesised silver nanoparticles for 1 hour reduction time.

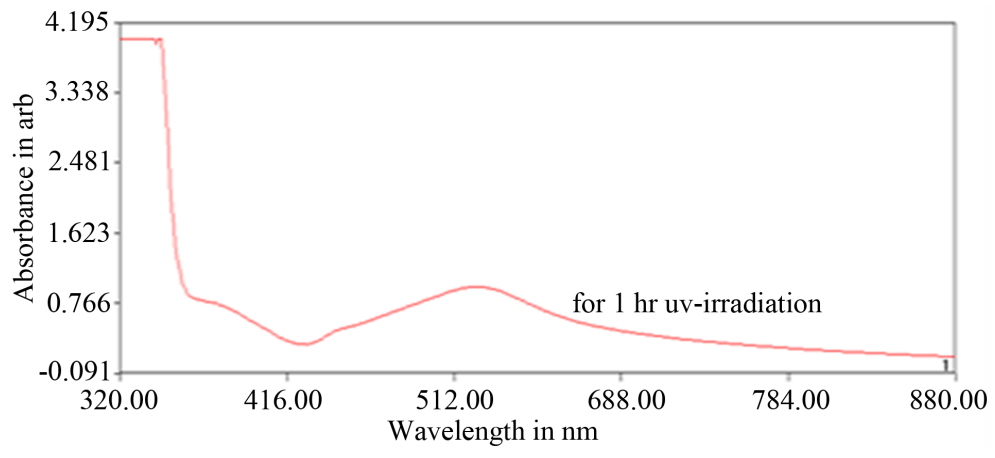

Figure 7. UV-visible spectroscopy of as-synthesised nanoparticles for 1 hour reduction time.

effective antimicrobial agent. The first comparative study on the bactericidal properties of silver particles of different shapes was conducted by Pal et al. [17]. In that work, differently morphological silver particles such as spherical, rod shaped and truncated triangular silver nanoparticles were used to treat microorganism. Interestingly, the truncated triangular nanoparticles displayed the strongest biocidal action, compared with the spherical and rod-shaped nanoparticles. Antibacterial activity of triangular shaped nanoparticle along with antibiotics ampicillin and gentamicin was studied against Staphylococcus aureus and Pseudomonas aeruginosa as triangular nano prism with sharp vertices and edges display higher antibacterial activity in comparison to other shapes of silver nanoparticles which finds these nanoparticles useful for biomedical applications [28]. Also a comparative study of antibacterial effect between the combination of silver nanoparticles with gentamicin and with ampicillin was conducted. Comparative table of zones of inhibition for individual antibiotics and the antibiotics in combination with silver nanoparticles is shown in Table 1.

Synergistic effects can be clearly observed for from Table 1 . We can see that in case of $P$. aeruginosa antibacterial activity is obtained for the combination of silver nanoparticles whereas for the antibiotic alone no activity is observed. Also for the rest of combinations antibacterial activity can be seen. The reason for the reduced size of inhibition zone for combinations as compared to individual antibiotics may be attributed to the improper dispersion of the sample in the petri dish. It is also observed that the inhibition zone size is almost equal against both bacteria for both the antibiotics suggesting existence of same chelation effect between the silver nanoparticles and antibiotics. The mechanism of the bactericidal effect of Ag NPs can be attributed to the fact that they possibly attach to the surface of the cell membrane disturbing permeability and respiration functions of the cell [29]. Sharp vertexes and sharp edges of triangular nano prism would be more toxic in damaging the bacterial cell [28]. 
Table 1. Comparative study of effect of silver nanoparticles in combination with two antibiotics for the configuration.

\begin{tabular}{|c|c|c|c|c|c|c|c|c|c|c|c|c|c|}
\hline \multirow{2}{*}{ S. No. } & \multirow{2}{*}{ Organism } & \multicolumn{3}{|c|}{ Zone size for ampicillin } & \multicolumn{3}{|c|}{$\begin{array}{l}\text { Zone size for sample } \\
\quad+\text { ampicillin }\end{array}$} & \multicolumn{3}{|c|}{$\begin{array}{l}\text { Zone size for } \\
\text { gentamicin }\end{array}$} & \multicolumn{3}{|c|}{$\begin{array}{l}\text { Zone for sample + } \\
\text { gentamicin }\end{array}$} \\
\hline & & P1 & $\mathrm{P} 2$ & Mean & $\mathrm{P} 1$ & P2 & Mean & $\mathrm{P} 1$ & P2 & Mean & $\mathrm{P} 1$ & $\mathrm{P} 2$ & Mean \\
\hline 1. & S. aureus & 42 & 46 & 44 & 22 & 20 & 21 & 28 & 30 & 29 & 20 & 18 & 19 \\
\hline 2. & P. aeruginosa & $\mathrm{RE}$ & $\mathrm{RE}$ & $\mathrm{RE}$ & 19 & 23 & 21 & 18 & 20 & 19 & 20 & 16 & 18 \\
\hline
\end{tabular}

Plate 1 = P1, Plate 2 = P2.

\section{Conclusion}

In the present work, the author to the best of her knowledge has tried a new way to synthesised silver nano particle of triangular shape using the basic principles of green technology. The average particle size obtained for the nanoparticles was $50 \mathrm{~nm}$. The most important feature of this procedure is that it does not involve usage of hazardous chemicals, which gives an edge over various chemical procedures usually applied for the synthesis of silver nanoparticles. A comparative antibacterial study between as-synthesised silver nanoparticles in combination with two standard antibiotics was analysed for a gram positive and a gram negative bacteria and it was found that the sample in combination with antibiotics is equally effective against both the bacteria. Synergistic effect for the combination in comparison to individual antibiotic ampicillin is clearly visible whereas for rest of the combinations possibly improper dispersion of the sample leads to smaller zone sizes.

\section{Acknowledgements}

Author is thankful to the Director, M.A.N.I.T., Bhopal, for the facilities at the institute, AMPRI Bhopal for XRD, for providing XRD facility, HSADL, Bhopal for the TEM facility.

\section{References}

[1] Knoll, B. and Keilmann, F. (1999) Near Field Probing of Vibrational Absorption for Chemical Microscopy. Nature, 399, 134-137.

[2] Sengupta, S., Eavarone, D., Capila, I., Zhao, G.L., Watson, N., Kiziltepe, T., et al. (2005) Temporal Targeting of Tumor Cells and Neovasculature with a Nanoscale Delivery System. Nature, 436, 568-572.

[3] Wiley, B., Sun, Y. and Xia, Y. (2007) Synthesis of Silver Nanostructures with Controlled Shapes and Properties. Accounts of Chemical Research, 40, 1067-1076.

[4] Ulkur, E., Oncul, O., Karagoz, H., Yeniz, E. and Celikoz, B. (2005) Comparison of Silver-Coated Dressing (Acticoat), Chlorhexidine Acetate 0.5\% (Bactigrass), and Fusidic Acid 2\% (Fucidin) for Topical Antibacterial Effect in Methicillin Resistant Staphylococci-Contaminated, Full-Skin Thickness Rat Burn Wounds. Burns, 31, 874-877.

[5] Parikh, D.V., Fink, T., Rajasekharan, K., Sachinvala, N.D., Sawhney, A.P.S., Calamari, T.A. and Parikh, A.D. (2005) Antimicrobial Silver/Sodium Carboxymethyl Cotton Dressings for Burn Wounds. Textile Research Journal, 75, 134-138.

[6] Alt, V., Bechert, T., Steinrücke, P., Wagener, M., Seidel, P., Dingeldein, E., Domann, E. and Schnettler, R. (2004) In Vitro Testing of Antimicrobial Activity of Bone Cement. Antimicrob Agents Chemother, 48, 4084-4088.

[7] Gosheger, G., Hardes, J., Ahrens, H., Streitburger, A., Buerger, H., Erren, M., Gunsel, A., Kemper, F.H., Winkelmann, W. and Von Eiff, C. (2004) Silver-Coated Megaendoprostheses in a Rabbit Model—An Analysis of the Infection Rate and Toxicological Side Effects. Biomaterials, 25, 5547-5556.

[8] Rupp, M.E., Fitzgerald, T., Marion, N., Helget, V., Puumala, S., Anderson, J.R. and Fey, P.D. (2004) Effect of Silver-Coated Urinary Catheters: Efficacy, Cost-Effectiveness, and Antimicrobial Resistance. American Journal of Infection Control, 32, 445-450.

[9] Samuel, U. and Guggenbichler, J.P. (2004) Prevention of Catheter-Rel the Potential of a New Nano Silver Impregnated Catheter. International Journal of Antimicrobial Agents, 23S1, S75-S78.

[10] Strathmann, M. and Wingender, J. (2004) Use of an Oxonol Dye in Combination with Confocal Laser Scanning Microscopy to Monitor Damage to Staphylococcus aureus Cells during Colonisation of Silver-Coated Vascular Grafts. International Journal of Antimicrobial Agents, 24, 234-240. http://dx.doi.org/10.1016/j.ijantimicag.2003.03.001

[11] Ohashi, S., Saku, S. and Yamamoto, K. (2004) Antibacterial Activity of Silver Inorganic Agent YDA Filler. Journal of Oral Rehabilitation, 31, 364-367. 
[12] Bosetti, M., Masse, A., Tobin, E. and Cannas, M. (2002) Silver Coated Materials for External Fixation Devices: In Vitro Biocompatibility and Genotoxicity. Biomaterials, 23, 887-892.

[13] Gauger, A., Mempel, M., Schekatz, A., Schafer, T., Ring, J. and Abeck, D. (2003) Silver Coated Textiles Reduce Staphylococcus aureus Colonization in Patients with Atopic Eczema. Dermatology, 207, 15-21.

[14] Lee, H.J. and Jeong, S.H. (2005) Bacteriostasis and Skin Innoxiousness of Nanosize Silver Colloids on Textile Fabrics. Textile Research Journal, 75, 551-556.

[15] Afreen, R.V. and Ranganath, E. (2011) Synthesis of Monodispersed Silver Nanoparticles by Rhizopus Stolonifer and Its Antibacterial Activity against MDR Strains of Pseudomonas Aeruginosa from Burnt Patients. International Journal of Environmental Sciences, 1, 1582-1592.

[16] Mirzajani, F., Ghassempour, A., Aliahmadi, A. and Esmaeili, M.A. (2011) Antibacterial Effect of Silver Nanoparticles on Staphylococcus aureus. Research in Microbiology, 162, 542-549.

[17] Pal, S., Tak, Y. and Song, J. (2007) Does the Antibacterial Activity of Silver Nanoparticles Depend on the Shape of the Nanoparticle? A Study of the Gram-Negative Bacterium Escherichia coli. Applied and Environmental Microbiology, 73, 1712-1720.

[18] Rajawat, S. and Qureshi, M.S. (2012) Comparative Study on Bactericidal Effect of Silver Nanoparticles, Synthesized Using Green Technology, in Combination with Antibiotics on Salmonella typhi. Journal of Biomaterials and Nanobiotechnology, 3, 480-485.

[19] Boldyrev, V.V. (2002) Thermal Decomposition of Silver Oxalate. Thermochimica Acta, 388, 63-90.

[20] Navaladian, S., Janet, C.M., Viswanathan, B., Varadarajan, T.K. and Viswanath, R.P. (2007) Afacile Room Temperature Synthesis of Gold Nanowires by Oxalate Reduction Method. The Journal of Physical Chemistry C, 111, 1415014156.

[21] Navaladian, S., Viswanathan, B., Viswanath, R.P. and Varadarajan, T.K. (2007) Thermal Decomposition as Route for Silver Nanoparticles. Nanoscale Research Letters, 2, 44-48.

[22] Mansouri, S.S. and Ghader, S. (2009) Experimental Study on Effect of Different Parameters on Size and Shape of Triangular Silver Nanoparticles Prepared by a Simple and Rapid Method in Aqueous Solution. Arabian Journal of Chemistry, 2, 47-53.

[23] Kasivelu, G., Sabjan, K., Vijayakumar Ganesh, K. and Ganesan, S. (2008) Silver, Gold and Bimetallic Nanoparticles Production Using Single-Cell Protein (Spirulinaplatensis) Geitler. Journal of Materials Science, 43, 5115-5122.

[24] Godapati, R.D. (1954) Cong. Luso-Esparn Farm. 3.

[25] Loo, Y.Y., Chieng, B.W. and Radu, M.N.S. (2012) Synthesis of Silver Nanoparticles by Using Tea Leaf Extract from Camellia Sinensis. International Journal of Nanomedicine, 7, 4263-4267.

[26] Joshi, M., Bhattacharyya, A. and Wazed Ali, S. (2008) Characterization Techniques for Nanotechnology Applications in Textiles. Indian Journal of Fibre and Textile Research, 33, 304-317.

[27] (2013) Electronic Supplementary Material (ESI) for Analyst. The Royal Society of Chemistry.

[28] Van Dong, P., Ha, C.H., Binh, L.T. and Kasbohm, J. (2012) Chemical Synthesis and Antibacterial Activity of NovelShaped Silver Nanoparticles. International Nano Letters, 1, 2-9.

[29] Kvitek, L., Panacek, A., Soukupova, J., Kolar, M., Vecerova, R., Prucek, R., et al. (2008) Effect of Surfactants and Polymers on Stability and Antibacterial Activity of Silver Nanoparticles (NPs). The Journal of Physical Chemistry C, 112, 5824-5825. 
Scientific Research Publishing (SCIRP) is one of the largest Open Access journal publishers. It is currently publishing more than 200 open access, online, peer-reviewed journals covering a wide range of academic disciplines. SCIRP serves the worldwide academic communities and contributes to the progress and application of science with its publication.

Other selected journals from SCIRP are listed as below. Submit your manuscript to us via either submit@scirp.org or Online Submission Portal.
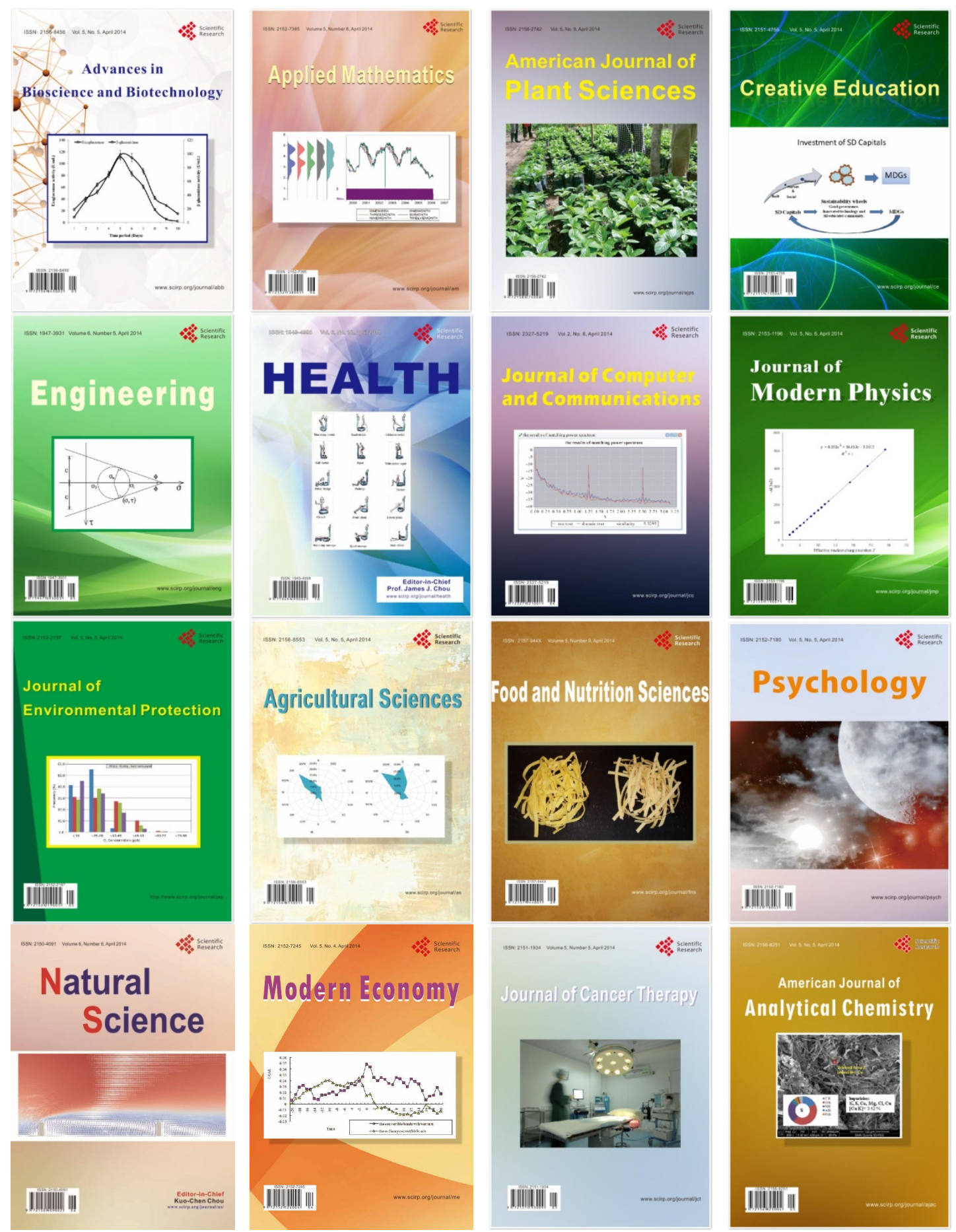